\title{
Presentation and treatment of acute maxillary sinusitis in general practice: A French observational study*
}

\author{
J-M. Klossek ${ }^{1}$, K. Mesbah' ${ }^{2}$ \\ 1 ENT and Head and Neck Department, University Hospital Jean Bernard Service, ORL, Poitiers Cedex, \\ France \\ 2 Schering-Plough, Levallois-Perret, France
}

SUMMARY

This survey-based study was conducted to determine the characteristics that influence the diagnosis and treatment patterns of acute maxillary sinusitis among general practitioners in France. Questionnaires were sent to 467 physicians and requested to be completed for the next 4 adult ( $\geq 15$ years) patients diagnosed with acute maxillary sinusitis. A total of 397 physicians responded with eligible data on 1585 patients ( $57.5 \%$ female; mean age, 42.3 years). The most common presenting signs and symptoms were moderate-to-severe nasal obstruction (80.4\%), pain on sinus palpitation (76.8\%), facial pain (74.5\%), rhinorrhea $(70.4 \%)$, and headache $(63.6 \%)$. Local treatments were prescribed in $93.2 \%$ of cases, including nasal lavage $(52.1 \%)$, vasoconstrictors (42.2\%), and intranasal corticosteroids (38.7\%). Almost all patients (99\%) were prescribed oral treatment including antibiotics (86.5\%), analgesics (56.3\%), antipyretics (53.7\%), and expectorants/mucolytics (45.6\%). Symptoms were indicated as having a moderate to very significant effect on quality of life areas including activities of daily living $(71.6 \%$ of patients), leisure (63.1\%), and professionallschool activities (59.2\%). The diagnosis and management patterns of acute maxillary sinusitis among general practitioners in France are generally consistent with the 2007 European Position Paper on Rhinosinusitis and Nasal Polyps $\left(E P^{3} \mathrm{OS}\right)$ guidelines.

Key words: maxillary sinusitis, quality of life, nasal obstruction, health care surveys, guideline adherence

\section{INTRODUCTION}

Acute maxillary sinusitis is defined as inflammation of the paranasal sinuses, characterized by symptoms of nasal blockage/congestion, anterior/posterior nasal drip, facial pain/pressure, and reduction or loss of smell for less than 12 weeks ${ }^{(1)}$. Because inflammation of the sinus mucosa is accompanied by inflammation of the contiguous nasal mucosa, the disorder is now commonly referred to as "rhinosinusitis" (1).

There is little information regarding the prevalence of acute maxillary sinusitis, mainly because of the long-time absence of standard guidelines for diagnosis. Data from the United States suggest that sinusitis affects an estimated $16 \%$ of the adult population each year ${ }^{(2)}$. The incidence of acute maxillary sinusitis appears to be increasing along with that of allergic rhinitis ${ }^{(1)}$, which has been suggested as a predisposing factor ${ }^{(3-5)}$. Data from the Netherlands for the year 2000 revealed that the incidence of general practice visits for acute sinusitis was 20 per 1000 men and 33.8 per 1000 women ${ }^{(1)}$.

Acute maxillary sinusitis is generally caused by an upper res- piratory tract viral infection. It has been estimated that only $0.2 \%$ to $2 \%$ of adult cases of viral upper respiratory tract infections are complicated by secondary bacterial infection ${ }^{(1,6,7)}$. Yet, antibiotic use remains extremely common, likely because of the difficulty in distinguishing between viral and bacterial etiology ${ }^{(8)}$. Complications from acute maxillary sinusitis are rare. Orbital, osseous, and endocranial sequelae may occur in rare cases of untreated or inadequately treated disease ${ }^{(1,9)}$. More commonly, acute maxillary sinusitis morbidity manifests in bothersome hallmark symptoms including nasal obstruction, sinus pain, and rhinorrhea. Nasal congestion, in particular, has been associated with sleep disturbances and daytime fatigue ${ }^{(10-13)}$. While acute maxillary sinusitis is assumed to have a considerable effect on health-related quality of life, and daily functioning, hard data are few.

The 2007 European Position Paper on Rhinosinusitis and Nasal Polyps $\left(\mathrm{EP}^{3} \mathrm{OS}\right)^{(1)}$ and the Agence Francaise de Sécurité Sanitaire des Produits de Santé ${ }^{(13)}$ provide evidence-based recommendations for the diagnosis and treatment of sinusitis. 
Diagnosis is primarily symptom-based (nasal obstruction or discharge \pm facial pain/pressure \pm reduced sense of smell) and presumed viral unless symptoms increase beyond 5-10 days' duration.

Recommended management for suspected bacterial rhinosinusitis includes intranasal corticosteroids, oral antibiotics for more severe cases, or both ${ }^{(1)}$. This therapeutic approach is becoming familiar in Europe, although not reflected in current French guidelines for management of acute maxillary sinusitis (14).

The primary objective of this survey-based study was to determine the disease characteristics influencing diagnosis of acute maxillary sinusitis among general practitioners in France. Data were also gathered regarding symptom patterns, quality of life impact, and treatment strategies.

\section{MATERIALS AND METHODS}

\section{Survey}

This was a survey-based study conducted in France between December 30, 2005 and April 2, 2007. Questionnaires regarding acute maxillary rhinosinusitis were mailed to 467 private practice general practitioners selected from a French national database and were to be returned by mail, after stratification by lottery for geographical location. The final sample was derived from 800 possible participants. Participating physicians were asked to complete a questionnaire for each of their next 4 consecutive patients $\geq 15$ years of age whom they diagnosed with acute maxillary sinusitis and who consented to participate. Patients with chronic rhinosinusitis, nasal/sinus tumours, or nasal/sinus trauma were excluded.

Diagnosis of acute maxillary sinusitis was based on the criteria outlined in the guidelines published by the Agence Francaise de Sécurité Sanitaire des Produits de Santé: rhinorrhea (purulent or nonpurulent), nasal congestion/obstruction, sinus pain which usually resolve spontaneously. Diagnosis of bacterial sinusitis was dependent on the presence of at least 2 of the 3 major criteria: persistent or increasing intraorbital sinus pain despite symptomatic treatment (analgesic, antipyretic, decongestant); unilateral sinus pain that increases when the head is bent forward, is pulsating, and/or peaks in the late afternoon or night; increased rhinorrhea and purulence (especially when unilateral). Presence of minor criteria supports a bacterial diagnosis: fever persisting for 3 days or nasal congestion/ obstruction, sneezing, throat discomfort, or cough persisting beyond 10 days ${ }^{(10)}$.

The questionnaire solicited information regarding patient socio-demographics, timeframe of the current episode, any self-medication instituted, previous history of sinusitis or other upper respiratory conditions, allergy and smoking history, presence of any concomitant conditions, diagnostic procedures performed, if any (e.g., x-rays, scans, blood tests, bacteriology, etc.), and prescribed treatment(s). The questionnaire solicited both objective signs of disease and patients' subjective rating of their symptoms on a 4 -point scale $(0=$ none to $3=$ very severe).

\section{RESULTS}

Physicians

Of 467 general practitioners contacted, 397 (85\%) returned completed surveys. Seventy-three percent of participating physicians were male; mean length of practice was $20.0 \pm 8.9$ years (range, 1-45 years). Eight regions of France (North, West, East, Centre, Paris and its suburbs, South, Southeast, and Southwest) were represented. Participants were most heavily concentrated in the Southeast (18.9\%), West (16.4\%), and Southwest (14.4\%), with a fairly similar distribution among the Centre-East (11.3\%), Paris Region (11.1\%), Centre (9.3\%), East $(9.3 \%)$, and North $(9.3 \%)$ regions. The areas represented by the participating physician practices were characterized evenly among "rural" (37\%), "urban" (34.3\%), and "semirural" $(28.7 \%)$. Historically, the mean percentage of consultations attributed to acute maxillary sinusitis in these physicians' practices ranged from $0.15 \%$ to $60 \%$ (mean, 6.3\%). Over the previous 12 months, physicians reported seeing a mean of 3.5 cases (range, 0-200) of complicated sinusitis per practice.

\section{Patients}

There were 1749 patients examined for inclusion in the survey population and $1585(90.6 \%)$ participated. Mean age was 42.3 years (range, $15-92)$ and $57.5 \%(n=912)$ were female. Current smokers numbered $452(28.6 \%)$. Nearly half of patients $(\mathrm{n}=$ 728; $45.9 \%$ ) reported an acute respiratory infection (sinusitis, rhinopharyngitis, or both) immediately preceding the present

Table 1. Most common ( $\geq 10 \%)$ signs and symptoms (moderate-tosevere intensity) of acute maxillary sinusitis and mean severity scores* across entire population $(\mathrm{n}=1587)$.

\begin{tabular}{lcc}
\hline Sign/symptom & $\begin{array}{c}\text { Percentage of } \\
\text { patients reporting } \\
\text { moderate-to-severe } \\
\text { intensity }\end{array}$ & $\begin{array}{c}\text { Mean severity } \\
\text { score* (SD) } \\
\text { overall }\end{array}$ \\
\hline Nasal obstruction & 80.4 & $1.99(0.74)$ \\
Bilateral obstruction & 70.8 & $1.99(0.85)$ \\
Pain on sinus palpitation & 76.8 & $1.93(0.83)$ \\
Facial pain & 74.5 & $1.78(0.81)$ \\
Rhinorrhea & 70.4 & $1.69(0.86)$ \\
Headache & 63.6 & $1.48(0.89)$ \\
Posterior nasal discharge & 53.8 & $1.41(0.96)$ \\
Problems with sense of smell & 47.0 & $1.38(0.86)$ \\
Asthenia & 44.9 & $1.30(0.87)$ \\
Inflammation of nasal mucosa & 44.8 & $1.31(0.87)$ \\
Fever & 44.6 & $1.19(0.93)$ \\
Sleeping problems & 39.2 & $1.11(0.98)$ \\
Pus in nasal fossae & 37.9 & $0.95(1.00)$ \\
Pain in teeth/jaw & 32.2 & $1.12(0.87)$ \\
Cough & 32.1 & $0.85(0.91)$ \\
Eye pain & 25.8 & $0.87(0.86)$ \\
Aches & 24.1 & $0.89(0.78)$ \\
Pharyngeal pain & 21.3 & $0.85(0.79)$ \\
Laryngeal irritation & 21.0 & $0.63(0.79)$ \\
Dysphonia & 15.9 & $0.72(0.78)$ \\
Sneezing & 15.8 & $0.59(0.73)$ \\
Cervical ganglia & 12.5 &
\end{tabular}

*Scale: $0=$ none, $1=$ not very severe, $2=$ moderately severe, $3=$ very severe. 
illness, and $17.1 \%(\mathrm{n}=270)$ suffered from allergic respiratory disease. About 1 out of 6 patients $(n=217 ; 13.8 \%)$ reported a history of chronic respiratory disease, with the majority $(175 / 217 ; 81.0 \%)$ being asthma. Patients acknowledging a previous history of sinusitis reported a mean of 1.9 episodes per year (range, 0-15).

\section{Presenting signs and symptoms}

The majority (99.1\%) of patients surveyed were presenting for the first time with this particular case of acute maxillary sinusitis. The mean onset of current symptoms before the office visit was $4.5 \pm 5.2$ days (range, 0-50 days). The most common moderate-to-severe symptoms included nasal obstruction (80.4\%), pain on sinus palpitation $(76.8 \%)$, facial pain $(74.5 \%)$, rhinorrhea $(70.4 \%)$, and headache $(63.6 \%)$. Other frequently reported signs and symptoms, with mean severity scores reflective of the entire surveyed population, are listed in Table 1.

Of patients reporting nasal obstruction, 57.6\% reported moderate severity and $22.8 \%$ rated it very severe; $70.8 \%$ reported bilateral symptoms. Sixty percent of patients characterized

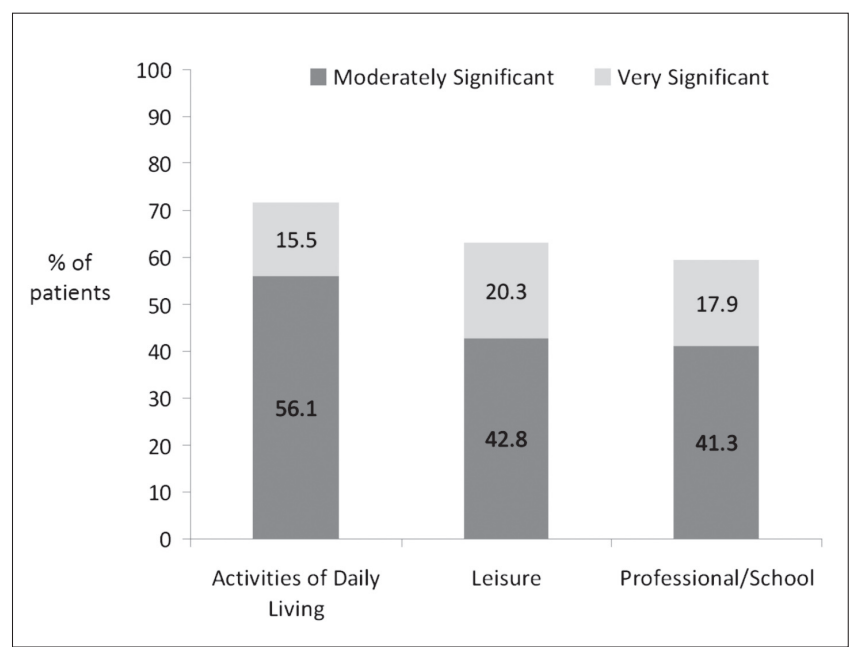

Figure 1. Percentage of patients reporting moderately or very significant interference with daily activities related to acute maxillary sinusitis symptoms.

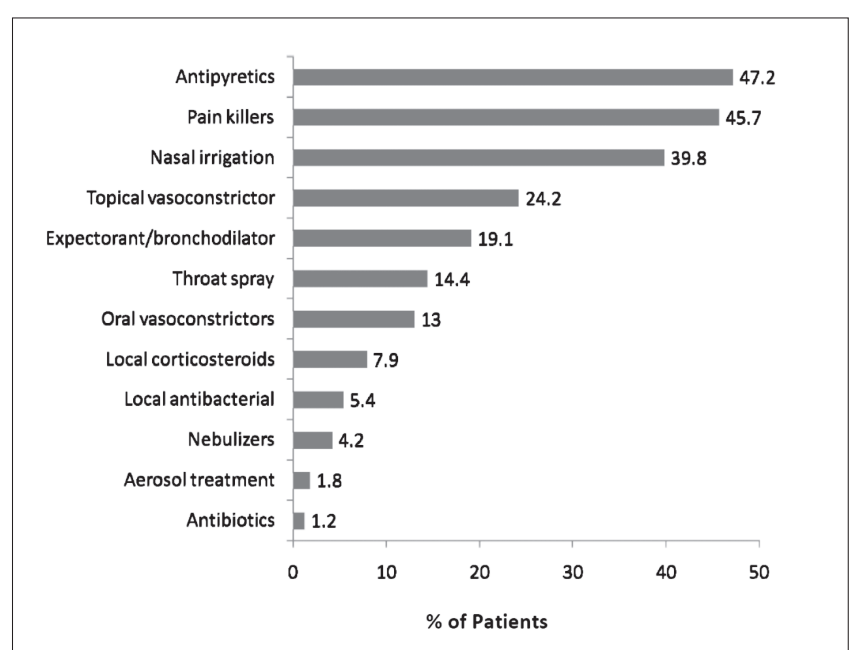

Figure 2. Self-medication reported among 1578 patients presenting with acute maxillary sinusitis. their nasal obstruction as "permanent.

Moderate-to-severe rhinorrhea was reported by $70.4 \%$ of patients. Most $(74.9 \%)$ was bilateral in nature. Posterior rhinorrhea was noted in $41.5 \%$ of these cases, anterior rhinorrhea in 33\%, and both anterior and posterior rhinorrhea in the remaining $25.4 \%$. In most cases $(78.4 \%)$, rhinorrhea was purulent.

\section{Diagnostic examinations}

Most patients (85.3\%) were diagnosed without any examinations beyond clinical signs and symptoms. Sinus $\mathrm{x}$-ray was used in $7.3 \%$ of cases, maxillo-facial scan in $1.9 \%$ of cases, and lung + sinus $\mathrm{x}$-ray in $1.8 \%$ of cases.

\section{Quality of Life Impact}

More than half of patients found acute maxillary sinusitis symptoms to moderately or very significantly interfere with activities of daily living, leisure activities, and professional/ school activities (Figure 1). A total of 459 (29.3\%) patients reported interrupted work activities (mean disruption period, $4.2 \pm 2.0$ days).

Symptoms rated most irritating included nasal obstruction (67.1\%), facial pain (53.2\%), headache (30.4\%), and rhinorrhea $(23.9 \%)$. Forty-three percent of patients reported 3 or more irritating symptoms, $42.9 \%$ reported $2,12.9 \%$ reported 1 , and only $1.2 \%$ reported none.

\section{Management}

Most patients (76.9\%) had self-medicated for the current episode, most commonly with antipyretics $(47.2 \%)$, pain killers (45.7\%), and nasal irrigation (39.8\%) (Figure 2).

Following diagnosis of acute maxillary sinusitis, treatment was prescribed for $99.9 \%$ of patients, with local/topical therapy for $93.2 \%$, including nasal lavage (52.1\%), topical vasoconstrictors $(42.2 \%)$, topical corticosteroids $(38.7 \%)$, and topical antibiotics $(12.0 \%)$. Oral medications were prescribed for $99.0 \%$ of patients; of these prescriptions, $86.5 \%$ were for antibiotics, $56.3 \%$ for analgesics, $53.7 \%$ for antipyretics, and $45.6 \%$ for expectorants/mucolytics.

Tables 2 and 3 show the most common local and oral treatments. In almost a quarter of $(21.4 \%)$ patients, both an oral antibiotic and oral steroid were prescribed, with or without other treatments. Combined oral and local treatment was used in $91.8 \%$ of patients $(n=1457)$; the most frequently reported combinations $(\geq 1.3 \%)$ are presented in Table 4 .

Twelve $(0.8 \%)$ patients were prescribed respiratory physiotherapy. Seventy-nine patients $(5 \%)$ were referred to another physician. Follow-up consultation was planned in $21.8 \%$ of cases at a mean interval of $12.5 \pm 10.7$ days (range, 2-84 days).

\section{DISCUSSION}

These survey results provide a broad overview of acute maxillary sinusitis symptoms at presentation, and confirm that French general practitioners are diagnosing in ways consistent with current $\mathrm{EP}^{3} \mathrm{OS}$ evidence-based treatment guidelines ${ }^{(1)}$. Diagnosis was made primarily on the basis of symptoms; both 
Table 2. Most common ( $\geq 2 \%$ ) local therapies prescribed for acute maxillary sinusitis (of 1471 patients given local treatment)*

\begin{tabular}{|c|c|c|c|c|c|}
\hline \multicolumn{5}{|c|}{ LOCAL TREATMENTS } & \multirow{2}{*}{$\begin{array}{c}\mathrm{N}=1471 \\
\mathrm{n}(\%)\end{array}$} \\
\hline $\begin{array}{l}\text { Vasocon- } \\
\text { strictor }\end{array}$ & Lavage & $\begin{array}{c}\text { Nasal } \\
\text { Steroids }\end{array}$ & $\begin{array}{c}\text { Topical } \\
\text { Antibiotic }\end{array}$ & Aerosol & \\
\hline \multirow[t]{4}{*}{$\mathrm{X}$} & & & & & $230(15.7)$ \\
\hline & $\mathrm{X}$ & & & & $189(12.9)$ \\
\hline & & $\mathrm{X}$ & & & $170(11.6)$ \\
\hline & $\mathrm{X}$ & $\mathrm{X}$ & & & $157(10.7)$ \\
\hline $\mathrm{X}$ & $\mathrm{X}$ & & & & $152(10.4)$ \\
\hline $\mathrm{X}$ & $\mathrm{X}$ & $\mathrm{X}$ & & & $52(3.5)$ \\
\hline \multirow[t]{4}{*}{$\mathrm{X}$} & & $\mathrm{X}$ & & & $43(2.9)$ \\
\hline & $\mathrm{X}$ & & $\mathrm{X}$ & & $42(2.9)$ \\
\hline & & & $\mathrm{X}$ & & $30(2)$ \\
\hline & & & & $\mathrm{X}$ & $30(2)$ \\
\hline
\end{tabular}

* Data do not signify monotherapy with local treatment, but are merely a breakdown of usage for specific treatment types of a local nature (may or may not have been in combination with oral treatments; see Table for oral + local combination regimens).
Table 3. Most common ( $\geq 2 \%$ ) oral treatments prescribed for acute maxillary sinusitis (of 1563 patients given oral treatment).

\begin{tabular}{cccccc}
\hline \multicolumn{2}{l}{ LOCAL TREATMENTS } & & & $\mathrm{N}=1563$ \\
\hline Antibiotics & Analgesic & Antipyretic & $\begin{array}{c}\text { Oral } \\
\text { steroid }\end{array}$ & Mucolytic & $\mathrm{n}(\%)$ \\
\hline $\mathrm{X}$ & $(\mathrm{X})$ & $(\mathrm{X})$ & $\mathrm{X}$ & $(\mathrm{X})$ & $335(21.4) \dagger$ \\
$\mathrm{X}$ & $\mathrm{X}$ & $\mathrm{X}$ & & & $164(10.5)$ \\
$\mathrm{X}$ & $\mathrm{X}$ & $\mathrm{X}$ & & $\mathrm{X}$ & $137(8.8)$ \\
$\mathrm{X}$ & & $\mathrm{X}$ & & $\mathrm{X}$ & $119(7.6)$ \\
$\mathrm{X}$ & $\mathrm{X}$ & & & & $114(7.3)$ \\
$\mathrm{X}$ & $\mathrm{X}$ & & & $\mathrm{X}$ & $106(6.8)$ \\
$\mathrm{X}$ & & $\mathrm{X}$ & & & $91(5.8)$ \\
$\mathrm{X}$ & & & & & $81(5.2)$ \\
$\mathrm{X}$ & & & & $\mathrm{X}$ & $78(5.0)$ \\
\hline
\end{tabular}

* Data do not signify monotherapy with oral treatment, but are merely a breakdown of usage for specific oral treatment types (may or may not have been in combination with local treatments; see Table for oral + local combination regimens).

$\dagger$ Data for this line inclusive of subjects on antibiotics and an oral steroid with and without analgesics, antipyretics, or mucolytics (x).
$\mathrm{EP}^{3} \mathrm{OS}$ and French guidelines recommend symptom-based diagnosis of acute maxillary sinusitis and discourage the use of sinus X-rays or CT scans.

Acute maxillary sinusitis had a significant burden on quality of life, which has not been well studied. Nearly $60 \%$ of patients indicated interference with work or school-related performance, which has not yet been investigated in acute maxillary sinusitis patients. Quality of life issues deserve further study and are recommended for inclusion in clinical trials of acute maxillary sinusitis interventions ${ }^{(15)}$.

Despite a lack of clear medical consensus regarding their appropriateness, the most common acute maxillary sinusitis treatment in our survey was oral antibiotics. French guidelines recommend symptomatic treatment of acute maxillary sinusitis unless bacterial infection is clearly evident (e.g., clearly localized, stereotypical pain, homolateral purulent rhinorrhea) ${ }^{(14)}$. The frequency of antibiotic use may reflect, at least in part, entrenched prescribing habits as well as patient expectations.

The EP ${ }^{3} \mathrm{OS}$ guidelines' (1) assessment of antibiotic use in acute maxillary sinusitis cites a 2003 Cochrane review concluding that 7 to 14 days of amoxicillin/penicillin may be warranted in cases confirmed by radiography or aspiration ${ }^{(16)}$. However, the guidelines ${ }^{(1)}$ also reference two subsequent studies ${ }^{(17,18)} \mathrm{dem}$ onstrating no significant benefit from antibiotic use and conclude that the preponderance of data suggest a limited role of antibiotics in acute maxillary sinusitis, aside from special circumstances such as immunodeficiency. The most recent (2008) Cochrane update, concurs that antibiotics have a limited efficacy in acute sinusitis and reiterates that $80 \%$ of cases will resolve without antibiotics within 2 weeks ${ }^{(19)}$.

Other common oral treatments, included analgesics and antipyretics, corresponding to the frequently reported pain. Usage of symptomatic medication is in accordance with current French guidelines, which recommend treating suspected nonbacterial rhinosinusitis with an antipyretic, analgesic, and/or

Table 4. Most common ( $\geq 1.3 \%$ ) oral + local treatment combination regimens prescribed for acute maxillary sinusitis (among 1457 patients treated with an oral + local combination).

\begin{tabular}{|c|c|c|c|c|c|c|c|c|c|c|}
\hline \multicolumn{3}{|c|}{ LOCAL TREATMENTS* } & \multicolumn{5}{|c|}{ ORAL TREATMENTS } & \multicolumn{3}{|c|}{$\mathrm{N}=1457$} \\
\hline $\begin{array}{l}\text { Vasocon- } \\
\text { strictor }\end{array}$ & Lavage & $\begin{array}{c}\text { Nasal } \\
\text { Steroid }\end{array}$ & $\begin{array}{c}\text { Topical } \\
\text { Antibiotic }\end{array}$ & Antibiotic & Analgesic & Antipyretic & $\begin{array}{c}\text { Oral } \\
\text { steroid }\end{array}$ & Mucolytic & $\mathrm{n}(\%)$ & $\begin{array}{c}\text { Cumulative } \\
\mathrm{n}(\%)\end{array}$ \\
\hline \multirow[t]{2}{*}{$\mathrm{X}$} & & & & $\mathrm{X}$ & $\mathrm{X}$ & $\mathrm{X}$ & & & $33(2.26)$ & $33(2.26)$ \\
\hline & $\mathrm{X}$ & & & $\mathrm{X}$ & $\mathrm{X}$ & $\mathrm{X}$ & $\mathrm{X}$ & & $32(2.20)$ & $65(4.46)$ \\
\hline \multirow[t]{2}{*}{$\mathrm{X}$} & & & & $\mathrm{X}$ & $\mathrm{X}$ & $\mathrm{X}$ & $\mathrm{X}$ & & $28(1.92)$ & $93(6.38)$ \\
\hline & $\mathrm{X}$ & & & $\mathrm{X}$ & & & $\mathrm{X}$ & & $25(1.72)$ & $118(8.10)$ \\
\hline \multirow[t]{2}{*}{$\mathrm{X}$} & & & & $\mathrm{X}$ & $\mathrm{X}$ & & & & $22(1.51)$ & $140(9.61)$ \\
\hline & $\mathrm{X}$ & & & $\mathrm{X}$ & & $\mathrm{X}$ & & $\mathrm{X}$ & $22(1.51)$ & $162(11.12)$ \\
\hline $\mathrm{X}$ & & & & $\mathrm{X}$ & & & $\mathrm{X}$ & & $20(1.37)$ & $182(12.49)$ \\
\hline $\mathrm{X}$ & & & & $\mathrm{X}$ & & $\mathrm{X}$ & $\mathrm{X}$ & & $19(1.30)$ & $201(13.80)$ \\
\hline \multirow[t]{4}{*}{$\mathrm{X}$} & & & & $\mathrm{X}$ & $\mathrm{X}$ & $\mathrm{X}$ & $X$ & $\mathrm{X}$ & $19(1.30)$ & $220(15.10)$ \\
\hline & $\mathrm{X}$ & & & $\mathrm{X}$ & $\mathrm{X}$ & $\mathrm{X}$ & & $\mathrm{X}$ & $19(1.30)$ & 239 (16.40) \\
\hline & $X$ & & & $X$ & & $X$ & $\mathrm{X}$ & $X$ & $19(1.30)$ & $258(17.71)$ \\
\hline & $X$ & & & $X$ & & & $\mathrm{X}$ & $\mathrm{X}$ & $19(1.30)$ & $277(19.01)$ \\
\hline
\end{tabular}

*Analysis for local treatments was limited to vasoconstrictor, lavage, and nasal steroid. 
vasoconstrictor for 2 to 3 days. These treatments frequently produce a cure ${ }^{(14)}$, thus limiting potential antibiotic use. Oral antihistamine use was rarely observed in our cohort, a practice consistent with clinical data showing no efficacy for antihistamines on symptoms of acute maxillary sinusitis unless allergy is present ${ }^{(20,21)}$.

Oral steroids were prescribed in (21.4\% of cases) despite French guideline recommendations to restrict their use to painful cases ( $>7$ on the $0-10$ VAS scale) ${ }^{(14)}$. In our survey, about $25 \%$ of respondents (309 patients) ranked their facial pain as "very severe." This prescribing trend may reflect the hypothesis that pain caused by inflammation must be treated separately.

Half of the prescribed local treatments were nasal lavage, which is recommended by $\mathrm{EP}^{3} \mathrm{OS}$ only for chronic sinusitis ${ }^{(1)}$. About $42 \%$ of patients were prescribed a local vasoconstrictor, recommended by $\mathrm{EP}^{3} \mathrm{OS}$ as a first-line treatment option for mild acute maxillary sinusitis in adults ${ }^{(1)}$. Oral vasoconstrictors were prescribed by just $12 \%$ of respondents (189 patients), likely reflecting the higher risk of adverse effects with oral administration.

Nearly $40 \%$ of patients in our survey were prescribed an intranasal corticosteroid for acute maxillary sinusitis, consistent with $\mathrm{EP}^{3} \mathrm{OS}$ guidelines recommending intranasal corticosteroids as first-line monotherapy for moderate cases and adding antibiotics only in severe cases ${ }^{(1)}$. As current French guidelines (2005) ${ }^{(14)}$ do not yet advocate routine intranasal corticosteroid use ${ }^{(14)}$ findings may imply a greater reliance on $\mathrm{EP}^{3} \mathrm{OS}$ recommendations among French general practitioners in this regard. It is also possible, given the $17 \%$ incidence of concomitant allergic disease in the survey population, that some of the intranasal corticosteroid use was targeted primarily at an underlying allergy.

Use of intranasal corticosteroids for acute maxillary sinusitis appears rational, particularly when the most common and bothersome symptom, in our survey is nasal obstruction, followed by pain on sinus palpitation and facial pain. Inflammation is considered a major mechanism responsible for these symptoms; a number of studies have confirmed the efficacy of intranasal corticosteroids in acute sinusitis, either as adjunctive therapy with antibiotics ${ }^{(17,22)}$ or as monotherapy. Of particular interest, the results of a large, double-blind, doubledummy study indicated that twice-daily intranasal corticosteroid use was significantly superior to amoxicillin or placebo in improving nasal symptom scores and did not result in disease recurrence or susceptibility to bacterial infection ${ }^{(17)}$.

In summary, it appears that most general practitioners are generally following $\mathrm{EP}^{3} \mathrm{OS}$ guidelines with regard to the diagnosis and management of acute maxillary rhinosinusitis. The hallmark symptoms of nasal congestion and sinus pain were detrimental to quality of life, and instrumental in diagnosis. Prescribing of symptomatic medications, except for an apparent overuse of mucolytics, adheres to current treatment rec- ommendations. Antibiotic use remains widespread, despite ongoing debate about inappropriate use in many cases, fuelled by concerns over resistance. Intranasal corticosteroids, which are evolving as an effective first-line management strategy for acute maxillary sinusitis, are already being commonly prescribed by French general practitioners.

\section{ACKNOWLEDGEMENT}

Editorial assistance was provided by Sandra Westra, PharmD. This assistance was funded by Schering-Plough Corporation, now Merck \& Co., Inc., Whitehouse Station, NJ, USA.

\section{REFERENCES}

1. Fokkens W, Lund V, Mullol J; European Position Paper on Rhinosinusitis and Nasal Polyps group. European position paper on rhinosinusitis and nasal polyposis. Rhinology 2007; 20: 1-136.

2. Slavin RG, Spector SL, Bernstein IL, et al. The diagnosis and management of sinusitis: a practice parameter update. J Allergy Clin Immunol 2005; 116 (suppl): S13-S47.

3. Chen C-F, Wu K-G, Hsu M-C, Tang R-B. Prevalence and relationship between allergic diseases and infectious diseases. $\mathrm{J}$ Microbiol Immunol Infect 2001; 34: 57-62.

4. Savolainen S. Allergy in patients with acute maxillary sinusitis. Allergy 1989; 44: 116-122.

5. Kirtsreesakul V, Naclerio RM. Role of allergy in rhinosinusitis. Curr Opin Allergy Clin Immunol 2004; 4: 17-23.

6. Hickner JM, Bartlett JG, Besser RE, et al. American Academy of Family Physicians; American College of Physicians-American Society of Internal Medicine; Centers for Disease Control; Infectious Diseases Society of America. Principles of appropriate antibiotic use for acute rhinosinusitis in adults: background. Ann Intern Med 2001; 134: 498-505.

7. Dosh SA, Hickner JM, Mainous AG 3rd, et al. Predictors of antibiotic prescribing for nonspecific upper respiratory infections, acute bronchitis, and acute sinusitis. An UPRNet study. Upper Peninsula Research Network. J Fam Pract 2000; 49: 407-414.

8. Sinus and Allergy Health Partnership. Antimicrobial treatment guidelines for acute bacterial rhinosinusitis. Otolaryngol Head Neck Surg 2004; 130 (1 suppl): 1-45.

9. Lang EE, Curran AJ, Patil N, et al. Intracranial complications of acute frontal sinusitis. Clin Otolaryngol 2001; 26: 452-457.

10. Craig TJ, Ferguson BJ, Krouse JH. Sleep impairment in allergic rhinitis, rhinosinusitis, and nasal polyposis. Am J Otolaryngol 2008; 29: 209-217.

11. Kenny TJ, Duncavage J, Bracikowski J, et al. Prospective analysis of sinus symptoms and correlation with paranasal computed tomography scan. Otolaryngol Head Neck Surg 2001; 125: 40-43.

12. Hiraki N, Suzuki H, Udaka T, et al. Snoring, daytime sleepiness, and nasal obstruction with or without allergic rhinitis. Arch Otolaryngol Head Neck Surg 2008; 134: 1254-1257.

13. Agence Francaise de Sécurité Sanitaire des Produits de Santé. Antibiotherapie par voie general en pratique courante dans les infections respiratoires hautes de l'adulte et d'enfant. October 2005. http://www.afssaps.fr/Infos-de-securite/Recommandationsde-bonne-pratique/Antibiotherapie-par-voie-generale-dans-lesinfections-respiratoires-recommandations-de-bonnes-pratique/ (language)/fre-FR. Accessed January 27, 2010.

14. Klossek JM, Chidiac C, Serrano E, for the Study Group of Infectious Rhinosinusitis II (SGIS II). Current position of the management of community-acquired acute maxillary sinusitis or rhinosinusitis in France and literature review. Rhinology 2005; (suppl 19): 1-33.

15. Meltzer EO, Hamilos DL, Hadley JA, et al. Rhinosinusitis: establishing definitions for clinical research and patient care. J Allergy Clin Immunol 2004; 114 (suppl): S155-S212.

16. Williams JW Jr, Aguilar C, Cornell J, et al. Antibiotics for acute maxillary sinusitis (Cochrane Review). Cochrane Database Syst Rev 2003(2): CD000243. 
17. Meltzer EO, Bachert $\mathrm{C}$, Staudinger $\mathrm{H}$. Treating acute rhinosinusitis: comparing efficacy and safety of mometasone furoate nasal spray, amoxicillin, and placebo. J Allergy Clin Immunol 2005; 116: $1289-1295$.

18. Merenstein D, Whittaker C, Chadwell T, et al. Are antibiotics beneficial for patients with sinusitis complaints? A randomized double-blind clinical trial. J Fam Pract 2005; 54: 144-151.

19. Ahovuo-Saloranta A, Borisenko OV, Kovanen N, et al. Antibiotics for acute maxillary sinusitis. Cochrane Database Syst Rev 2008; (2): CD000243.

20. Braun JJ, Alabert JP, Michel FB, et al. Adjunct effect of loratadine in the treatment of acute sinusitis in patients with allergic rhinitis. Allergy 1997; 52: 650-655.

21. Sutter AI, Lemiengre M, Campbell H, et al. Antihistamines for the common cold. Cochrane Database Syst Rev 2003; CD001267.

22. Barlan IB, Erkan E, Bakir M, et al. Intranasal budesonide spray as an adjunct to oral antibiotic therapy for acute sinusitis in children. Ann Allergy Asthma Immunol 1997; 78: 598-601.

23. Dolor RJ, Witsell DL, Hellkamp AS, et al. Ceftin and Flonase for Sinusitis (CAFFS) Investigators. Comparison of cefuroxime with or without intranasal fluticasone for the treatment of rhinosinusitis. The CAFFS Trial: a randomized controlled trial. JAMA 2001; 286: 3097-3105.
24. Meltzer EO, Charous BL, Busse WW, et al, and the Nasonex Sinusitis Group. Added relief in the treatment of acute recurrent sinusitis with adjunctive mometasone furoate nasal spray. $\mathbf{J}$ Allergy Clin Immunol 2000; 106: 630-637.

25. Meltzer EO, Orgel HA, Backhaus JW, et al. Intranasal flunisolide spray as an adjunct to oral antibiotic therapy for sinusitis. J Allergy Clin Immunol 1993; 92: 812-823.

26. Nayak AS, Settipane GA, Pedinoff A, et al. Effective dose range of mometasone furoate nasal spray in the treatment of acute rhinosinusitis. Ann Allergy Asthma Immunol 2002; 89: 271-278.

Jean-Michel Klossek

CHU Jean Bernard

Service ORL, BP 577

86021 Poitiers Cedex

France

Tel: +33-(0)5-49-44 4328

Fax: +33-(0)5-49-44-3848

E-mail: j.m.klossek@chu-poitiers.fr 